\title{
Relationship Between the Oral Hygiene and Hand Hygiene Practices of Korean Adolescents: A Study Focused on the 15th Korea Youth Risk Behavior Survey Conducted in 2019
}

\author{
Eun-Jeong Kim \\ Department of dental Hygiene, Gangdong University \\ HYEJU LEE ( $\sim$ raeju0329@gmail.com ) \\ Dental Research Institute, Seoul National University
}

Research article

Keywords: Oral hygiene, Hand hygiene, Tooth brushing, Hand washing, Adolescent, KYRBS

Posted Date: January 25th, 2021

DOl: https://doi.org/10.21203/rs.3.rs-151822/v1

License: (a) This work is licensed under a Creative Commons Attribution 4.0 International License. Read Full License 


\section{Abstract}

Background: Hand hygiene is one of the most important measures available to prevent infectious diseases such as COVID-19, and it is recommended that individuals was their hands periodically before and after meals, after using toilets, before preparing food at home, at schools and in public places. The aim of this study was to investigate the relationship between oral hygiene and hand hygiene in Korean adolescents.

Method: Data from 57,303 adolescents who participated in the 2019 Korea Youth Risk Behavior Web-based Survey were analyzed to determine the relationship between oral hygiene and hand hygiene.

Results: According to the results of this study, adolescents who brushed their teeth after lunch were 1.48 times more likely to practice hand washing before lunch than were those who did not brush their teeth after lunch. In addition, the odds ratio adjusted for gender, grade, school type, and residence was found to be 1.87.

Conclusions: Oral hygiene practices were found to be related to personal hygiene, as assessed by hand washing, in Korean adolescents. Additional studies are needed to develop ways of improving the hygiene and health of adolescents.

\section{Background}

At the end of 2019, with the outbreak of an acute respiratory disease known as COVID-19 and its spread worldwide, the World Health Organization (WHO) issued guidelines on the prevention and control of infectious diseases. According to the guidelines, hand hygiene is one of the most important measures available to prevent infectious diseases such as COVID-19, and it is recommended that individuals was their hands periodically before and after meals, after using toilets, before preparing food at home, at schools and in public places [1]. Other prior studies have also reported that hand washing can prevent a number of infectious diseases, such as SARS, food poisoning, the common cold, influenza, and epidemic eye diseases; moreover, handwashing alone using regular soap can reduce the incidence of pneumonia, bacterial dysentery and diarrhea by $40-50 \%$ [2]. Thus, hand washing is the easiest way to prevent germs and viruses from spreading.

According to a study conducted on hand washing among adolescents in Korea, 13,153 (18.5\%) adolescents do not wash their hands before meals at school, indicating that continuous monitoring is necessary [3]. In addition, research on annual hand washing practice rates showed that hand washing practices were significantly higher in 2009 , likely due to the prevalence of the swine flu and the consequent effects of hygiene education [4]. Therefore, properly informing adolescents about health concepts and hygiene habits can have a large impact on the prevention of infectious diseases and can serve as a foundation for the promotion of health in adulthood, so continuous monitoring is necessary.

Adolescence is a very important period in which the permanent dentition develops through mixed dentition. The recognition of appropriate oral health practices in this period and efforts to promote oral health in adulthood are important factors for maintaining oral health [5]. It has also been reported that oral hygiene practices in adolescence are one of the most important ways to control and prevent oral diseases [6, 7]. According to a study on the relationship between oral health practices and oral disease symptoms in Korean adolescents, adolescents with severe oral disease symptoms and poor oral health practices were reported to 
be at risk for developing poor oral hygiene and poor oral health practices [8]. Another prior study found that $15.7 \%$ of female students aged 12 to 18 years old who brushed their teeth more than three times a day and $73.9 \%$ of those who did not brush their teeth at all developed periodontal diseases [9]. However, the average tooth brushing practice rate after lunch, a leading indicator of oral health practices, was $36.9 \%$ among adolescents, whereas it was $25.4 \%$ for middle school students and $52.2 \%$ for high school students, and problems with oral health practices in adolescents were reported [10].

To date, studies related to oral hygiene and personal hygiene in adolescence have been conducted, but most of the studies were cross-sectional studies that reported the statuses at one time point, and studies on their associations are lacking. Therefore, the purpose of this study was to provide basic information important for establishing health education in schools and preparing health promotion measures by determining the association between oral hygiene, as assessed by toothbrush use, and personal hygiene, as assessed by hand washing.

\section{Methods}

\section{Study subjects and study design}

This study was conducted by using raw data from the 15th Korea Youth Risk Behaviors Survey conducted in 2019 [11]. This survey is an online anonymous survey that does not collect any personal information of the participants, and is a nationally approved statistical survey (No. 117058) that has been approved by the state in accordance with Article 18 of the Statistical Act of the Republic of Korea, not approved by the institutional ethics committee. All students who participated in the survey participated in the survey after informed consent. A total of 57,303 middle and high school students from a total of 800 schools nationwide participated in the survey. The extraction frames at the sampling stage were used to retrieve data from middle and high schools nationwide in April 2018, and the high schools were divided into general and specialized high schools on the basis of the classification of the extraction frames. In the population stratification phase, to minimize sampling error, 39 local groups and school levels were used as stratification variables to divide the population into 117 layers. Local provinces were classified into 17 metropolitan cities, small and medium cities, and 39 cities were classified by geographical accessibility, the number of schools, population size, the living condition, the smoking rate, and the alcohol drinking rate. In the sample allocation phase, the sample size was 400 middle schools and 400 high schools, and five middle and high schools were selected from each of the 17 cities and provinces. The proportional allocation method was used to match the study population and overall population compositions by the variables used for stratification, and the number of sample schools was determined according to city and province (large city, small and medium city, county area), local province, middle school (male and female), engineering high school (male and female), general high school, and specialized high school. The sampling method was used for stratified colony extraction, with the primary extraction unit being school and the secondary extraction unit being class. For the first extraction, sample schools were selected using the permanent random number extraction method for each strata. The secondary extraction was performed at random from the selected sample schools with one class per grade [11].

\section{Survey Methods}


The variables used in this study consisted of a total of six, four concerned the general characteristics of the study subjects, one concerned their tooth brushing practice and one concerned their hand washing practice. The general characteristics that were investigated included gender, school type (male and female engineering, male and female general schools), grade year and type of residence (large city, small city and province area). Oral hygiene, which was assessed by tooth brushing practice, was investigated by dividing the survey data by the frequency at which individual brushed their teeth after lunch, creating two groups. Personal hygiene, as assessed by hand washing practice, was examined by dividing the survey data by the frequency at which the individuals washed their hands, creating two groups: those who did and did not wash their hands before meals at school. 'An additional file shows this in more detail [see Additional file 1]

\section{Statistical analysis}

A frequency analysis of the complex samples was conducted to assess the distributions of the demographic and sociological characteristics of the study subjects. A cross-analysis of the complex samples was conducted to determine whether individuals used a toothbrush after lunch and whether they washed their hands before a meal at school. A complex sample logistic regression analysis was performed to determine whether there was an association between hand washing practices and tooth brushing practices. The data were analyzed using SPSS 19.0 (IBM Co., Armonk, NY, USA), and the significance level was 0.05.

\section{Results}

\section{General Characteristics Of The Study Subjects}

The general characteristics of the study subjects are shown in Table 1. A total of 57,303 students were included, including 29,841 male students and 27,462 female students. Regarding the school types, $65.9 \%$ were coeducational, $17.2 \%$ were all-male schools and $16.9 \%$ were all-female schools. Large cities accounted for $42.5 \%$ of the residences, and small and medium-sized cities accounted for $51.9 \%$. 
Table 1

General characteristics of the study subjects

\begin{tabular}{|c|c|c|c|}
\hline Variable & & $\mathbf{N}$ & $\%$ \\
\hline \multirow[t]{2}{*}{ Gender } & Boys & 29,841 & 52 \\
\hline & Girls & 27,462 & 48 \\
\hline \multirow[t]{3}{*}{ School type } & Coeducation & 37,935 & 65.9 \\
\hline & All-boys schools & 9,818 & 17.2 \\
\hline & All-girls schools & 9,550 & 16.9 \\
\hline \multirow[t]{6}{*}{ Grade } & Middle school, 1st grade & 9,738 & 15.9 \\
\hline & Middle school, 2nd grade & 9,665 & 15.3 \\
\hline & Middle school, 3rd grade & 9,981 & 16.6 \\
\hline & High school, 1st grade & 9,273 & 17.1 \\
\hline & High school, 2nd grade & 9,044 & 16.5 \\
\hline & High school, 3rd grade & 9,602 & 18.5 \\
\hline \multirow[t]{3}{*}{ Residence type } & Metropolis & 25,335 & 42.5 \\
\hline & City & 27,471 & 51.9 \\
\hline & Rural area & 4,497 & 5.6 \\
\hline
\end{tabular}

\section{Whether tooth brushing and hand washing practices after lunch were associated with general characteristics}

Table 2 shows the tooth brushing and hand washing practices stratified by the general characteristics of the subjects. After lunch, $69.2 \%$ of female students brushed their teeth, which was statistically significantly higher than that of male students who brushed their teeth, which was $52.5 \%(p<0.001)$; moreover, this rate was $70.0 \%$ for all-female schools, which was significantly higher than those for coeducational (60.2\%) and all-male schools $(52.5 \%)(p<0.001)$. The rate was significantly higher for school students than for middle school students, and significant differences were found at each grade level $(p<0.001)$. A total of $54.8 \%$ of students in large cities, $63.2 \%$ of students in small and medium cities, and $79.1 \%$ of students in military districts brushed their teeth after lunch, and the highest rate of practice was in military districts. 
Table 2

Tooth brushing and hand washing practice data stratified by the general characteristics of the subjects

Variable

The practice of tooth brushing after a
meal

Yes

No

p-
value

The practice of hand washing before a meal

Yes No

p-value

\begin{tabular}{|c|c|c|c|c|c|c|}
\hline \multicolumn{7}{|l|}{ Gender } \\
\hline Boys & $\begin{array}{l}16,034 \\
(52.5)\end{array}$ & $\begin{array}{l}13,807 \\
(47.5)\end{array}$ & \multirow[t]{2}{*}{$<.001$} & $26,143(87.2)$ & $3,698(12.8)$ & \multirow[t]{2}{*}{$<0.001$} \\
\hline Girls & $\begin{array}{l}19,251 \\
(69.2)\end{array}$ & $8,211(30.8)$ & & $22,274(80.7)$ & $5,188(19.3)$ & \\
\hline \multicolumn{7}{|l|}{ School type } \\
\hline Coeducation & $\begin{array}{l}23,590 \\
(60.2)\end{array}$ & $\begin{array}{l}14,345 \\
(39.8)\end{array}$ & \multirow[t]{3}{*}{$<.001$} & $32,353(84.9)$ & $5,582(15.1)$ & \multirow[t]{3}{*}{$<0.001$} \\
\hline Boys' & $5,062(52.5)$ & $4,756(47.5)$ & & $8,527(86.2)$ & $1,291(13.8)$ & \\
\hline Girls' & $6,633(70.0)$ & $2,917(30.0)$ & & 7,537 (78.6) & $2,013(21.4)$ & \\
\hline \multicolumn{7}{|l|}{ Grade } \\
\hline $\begin{array}{l}\text { Middle school } \\
1 \mathrm{st}\end{array}$ & $5,271(51.8)$ & $4,467(48.2)$ & \multirow[t]{6}{*}{$<.001$} & $8,823(90.1)$ & $915(9.9)$ & \multirow[t]{6}{*}{$<0.001$} \\
\hline $\begin{array}{l}\text { Middle school } \\
\text { 2nd }\end{array}$ & $4,996(49.5)$ & $4,669(50.5)$ & & $8,346(85.7)$ & $1,319(14.3)$ & \\
\hline $\begin{array}{l}\text { Middle school } \\
\text { 3rd }\end{array}$ & $5,293(50.9)$ & $4,688(49.1)$ & & $8,397(83.7)$ & $1,584(16.3)$ & \\
\hline High school 1st & $6,101(63.9)$ & $3,172(36.1)$ & & $7,690(82.9)$ & $1,583(17.1)$ & \\
\hline High school 2nd & $6,399(69.5)$ & $2,645(30.5)$ & & $7,469(82,7)$ & $1,575(17.3)$ & \\
\hline High school 3rd & $7,225(74.7)$ & $2,377(25.3)$ & & $7,692(80.1)$ & $1,910(19.9)$ & \\
\hline \multicolumn{7}{|l|}{ Residence type } \\
\hline Metropolis & $\begin{array}{l}14,210 \\
(54.8)\end{array}$ & $\begin{array}{l}11,125 \\
(45.2)\end{array}$ & \multirow[t]{3}{*}{$<0.001$} & $21,384(84.1)$ & $3,951(15.9)$ & \multirow[t]{3}{*}{0.115} \\
\hline City & $\begin{array}{l}17,505 \\
(63.2)\end{array}$ & $9,966(36.8)$ & & $23,110(83.8)$ & $4,361(16.2)$ & \\
\hline Rural area & $3,570(79.1)$ & $927(20.9)$ & & $3,923(86.2)$ & $574(13.8)$ & \\
\hline
\end{tabular}

Values are presented as weighted percentages.

The $p$-values were obtained from the complex samples crosstabs panel in SPSS. 
Regarding the rate of practicing hand washing before eating at school, $87.2 \%$ of the male students practiced it, which was statistically significantly higher than that of female students, $80.7 \%(p<0.001)$; moreover, the rate was $86.2 \%$ for all-male schools, which was significantly higher that those at coeducational (84.9\%) and allfemale schools $(78.6 \%)(p<0.001)$. Middle school students showed a higher rate of hand washing than did high school students, and significant differences were found at each grade level $(p<0.001)$. In the classification according to the type of residence, the military area showed the highest hand washing practice rate at $86.2 \%$, but no significant difference was observed.

\section{Association Between Tooth Brushing And Hand Washing}

Table 3 shows the results of the analysis of the association between tooth brushing and hand washing practices. Adolescents who practiced tooth brushing after lunch were 1.48 times more likely to practice hand washing before meals at school than were those who did not practice tooth brushing after lunch $(p<0.001)$. In addition, an analysis of the association between tooth brushing and washing hands, after adjusting for gender, grade, school type, and residence, showed that adolescents who practiced tooth brushing after lunch were 1.87 times more likely to practice hand washing before meals at school than were those who did not $(p<0.001)$.

Table 3

Relationship between tooth brushing and hand washing

\begin{tabular}{|llllll|}
\hline Independent variable & Dependent variable & \multicolumn{2}{l}{ Model 1 } & \multicolumn{3}{l|}{ Model 2 } \\
\cline { 3 - 6 } & & Crude OR & $\mathbf{9 5 \%} \mathrm{Cl}$ & Adjusted OR $^{*}$ & 95\% Cl \\
\hline Tooth brushing practice & $\begin{array}{c}\text { Hand washing practice } \\
\text { (ref.no) }\end{array}$ & 1.48 & $1.40-1.57$ & 1.87 & $1.77-1.98$ \\
\hline OR: odds ratio, Cl: confidence interval & & & & \\
\hline * Adjusted for gender, school type, grade, residence type & & & \\
\hline
\end{tabular}

\section{Association between tooth brushing and hand washing practice in relation to personal hygiene education}

The association between tooth brushing and hand washing practice is shown in Table 4. An analysis of students who participated in personal hygiene education at school within the last 12 months showed that adolescents who brushed their teeth after lunch were 1.66 times more likely to wash their hands before lunch at school than were adolescents who did not brush their teeth after lunch $(p<0.001)$. In addition, an analysis of the association between tooth brushing and hand washing practices, after adjusting for gender, grade, school type and residence, showed that adolescents who practice tooth brushing after lunch are 1.98 times more likely to practice hand washing before lunch at school than are those who do not brush their teeth after lunch $(p<0.001)$. An analysis of adolescents who did not participate in personal hygiene education at school showed that adolescents who practiced tooth brushing after lunch were 1.45 times more likely to practice hand 
washing before meals at school within the last 12 months $(p<0.001)$. Furthermore, an analysis of the association between tooth brushing and hand washing practices, after adjusting for gender, grade, school type, and residence, showed that adolescents who brush their teeth after lunch are 1.80 times more likely to practice hand washing before lunch at school than are those who do not brush their teeth after lunch $(p<0.001)$.

Table 4

Relationship between tooth brushing and hand washing stratified by students' health education experience in school

\begin{tabular}{|c|c|c|c|c|c|c|c|c|c|}
\hline \multirow{4}{*}{$\begin{array}{l}\text { Independent } \\
\text { variable }\end{array}$} & \multirow{4}{*}{$\begin{array}{l}\text { Dependent } \\
\text { variable }\end{array}$} & \multicolumn{8}{|c|}{ Health education experience in school } \\
\hline & & \multicolumn{4}{|l|}{ Yes } & \multicolumn{4}{|l|}{ No } \\
\hline & & \multicolumn{2}{|c|}{ Model 1} & \multicolumn{2}{|l|}{ Model 2} & \multicolumn{2}{|c|}{ Model 1} & \multicolumn{2}{|l|}{ Model 2} \\
\hline & & $\begin{array}{l}\text { Crude } \\
\text { OR }\end{array}$ & $\begin{array}{l}95 \% \\
\mathrm{Cl}\end{array}$ & $\begin{array}{l}\text { Adjusted } \\
\mathrm{OR}^{*}\end{array}$ & $\begin{array}{l}95 \% \\
\mathrm{Cl}\end{array}$ & $\begin{array}{l}\text { Crude } \\
\text { OR }\end{array}$ & $\begin{array}{l}95 \% \\
\mathrm{Cl}\end{array}$ & $\begin{array}{l}\text { Adjusted } \\
\mathrm{OR}^{*}\end{array}$ & $\begin{array}{l}95 \% \\
\mathrm{Cl}\end{array}$ \\
\hline $\begin{array}{l}\text { Tooth } \\
\text { brushing } \\
\text { practice }\end{array}$ & $\begin{array}{l}\text { Hand } \\
\text { washing } \\
\text { practice } \\
\text { (ref.no) }\end{array}$ & 1.66 & $\begin{array}{l}1.51- \\
1.82\end{array}$ & 1.98 & $\begin{array}{l}1.80- \\
2.19\end{array}$ & 1.45 & $\begin{array}{l}1.35- \\
1.54\end{array}$ & 1.8 & $\begin{array}{l}1.68- \\
1.92\end{array}$ \\
\hline \multicolumn{10}{|c|}{ OR: odds ratio, Cl: confidence interval } \\
\hline * Adjusted fol & gender, schoo & type, $g$ & e, resi & ce type & & & & & \\
\hline
\end{tabular}

\section{Discussion}

In this study, according to the analysis of the practice of washing hands before lunch according to gender, male students showed significantly higher practice rates than did female students. This finding is inconsistent with previous research results, with the reported gender-based hand washing practice rate in three South Pacific island countries being significantly higher for girls than boys [12]. These results were also found in the Health Behavior in School-aged Children (HBSC) study and other prior studies conducted in Europe [13, 14]. These results can be explained in part by the implementation of health education programs for women and adolescents classified as underprivileged in communities in the countries of concern, but additional studies on the association between gender and personal hygiene are expected to be needed in the future, considering the national health policies. In addition, this study showed that the rate of hand washing was lower among high school students than among middle school students, and a prior study showed that as the students' grade in high school increased, the number of students who said they did not wash their hands before lunch at school significantly increased. As a result, more careful monitoring and ongoing research on demographic and sociological factors affecting the practice of personal hygiene in schools are required [1]. Good hand hygiene can prevent the occurrence of various diseases. In a randomized controlled study that evaluated the effects of hand washing using soap on acute respiratory tract infection, agro-vacuum and diarrhea prevention, the incidence of pneumonia in the hand washing group was $50 \%$ lower than that of the control group, $34 \%$ lower than that of the hand washing intervention group; moreover, hand washing with soap led to a $53 \%$ lower incidence of diarrhea [15]. It has also been reported that handwashing serves to reduce the spread of infectious diseases such as influenza, parasites, trachoma, neonatal infections, HIV-related infections and 
enteritis [16-20]. Therefore, studies on how to habituate hand washing, which is most effective in reducing disease burden, during adolescence need to be conducted.

Insufficient oral hygiene-related behaviors in adolescence, such as an insufficient frequency of tooth brushing, increase the incidence of dental caries and, as a result, adversely affect not only the quality of life of adolescents but also the health of adults [21.22]. The practice of tooth brushing after lunch was analyzed in this study, and $69.2 \%$ of female students and $52.5 \%$ of male students were found to perform this behavior, and the difference between groups was statistically significant. Similar results were found in previous studies. In a study on the tooth brushing practice of 231 Korean middle and high school students that was conducted using the 2017 Korean National Health and Nutrition Survey data, male students brushed their teeth 2.43 times per day and female students brushed them 2.64 times per day [23]. In addition, the rate of high school students who brushed their teeth after lunch was significantly higher than that of middle school students who brushed their teeth after lunch, and significant differences were identified across grade levels, which is consistent with the results in previous studies [24]. Behaviors related to oral health in adolescence can easily become habits, and it is a very important period in which behavioral changes in oral health are possible because it is the transition period from childhood to adulthood. Therefore, it is considered necessary to develop a systematic oral health education program along with a multifaceted analysis of factors affecting oral health behaviors in adolescence.

The results of this study showed that adolescents who brush their teeth after lunch are significantly more likely to practice hand washing before lunch at school than are those who do not brush their teeth after lunch, and an association between oral hygiene and personal hygiene was confirmed. These results are consistent with those in previous studies, and $50.1 \%$ of students who brushed their teeth more than once a day always washed their hands after visiting the restroom, indicating that tooth brushing is closely related to personal hygiene habits [25]. In addition, in a previous study conducted in middle school students from 15 Latin American countries, students who rarely brushed their teeth were 6.7 times more likely to wash their hands than were those who brushed their teeth more often, and the results of an analysis of these associations by gender also confirmed a significant association [26].

In this study, the positive association between tooth brushing and hand washing was found to be stronger in adolescents who participated in health education. These results are consistent with those in prior research, which have reported a $28.2 \%$ improvement in hand washing behavior and a $7.2 \%$ improvement in tooth brushing twice a day after hygiene education programs were implemented to improve knowledge and attitudes about hand washing and tooth brushing [27]. These results suggest that health promotion programs are needed to improve the hygiene-related behaviors of adolescents. The education, knowledge, and attitude of adolescent students regarding health hygiene are thought to have a large impact on hygiene practice as well as on the students' family and community. However, even if a school implements a health education program for personal hygiene management, it is difficult for students to perform personal hygiene management if the environment for tooth brushing and hand washing is poor; thus, the environment should be maintained, and a systematic health education program suitable for students should be developed and implemented.

Schools provide an important environment for the promotion of health at the most influential stage of individuals' lives, during which individuals should develop sustainable health behaviors and maintain them 
throughout their entire lives [28]. Therefore, the development and implementation of comprehensive and systematic school-based oral health promotion programs is necessary. Based on these findings, it is believed that comprehensive and systematic health policies are needed to improve youth hygiene and health.

\section{Conclusions}

Oral hygiene practices were found to be related to personal hygiene, as assessed by hand washing, in Korean adolescents. Additional studies are needed to develop ways of improving the hygiene and health of adolescents.

\section{Abbreviations}

COVID

Coronavirus disease

SARS

Severe Acute Respiratory Syndrome

HIV

Human Immunodeficiency Virus

\section{Declarations}

\section{Ethics approval and consent to participate}

The data used in this study was an online anonymous survey that did not collect any personal information of the participants. It was not approved by the institutional ethics committee, but was a nationally approved statistical survey (No. 117058) that was approved by the state according to Article 18 of the Statistical Law of the Republic of Korea. . All students who participated in the survey participated in the survey after informed consent.

\section{Consent for publication}

Not applicable.

\section{Availability of data and materials}

The datasets analysed during the current study are available in the website of KYRBWS, [(http://www.kdca.go.kr/yhs/]

\section{Competing Interests}

The authors declare that they have no competing interests.

\section{Funding}

No funding. 


\section{Author's Contributions}

Conceptualization: HJL; Formal analysis: HJL; Investigation: HJL; Methodology: EJK; Project administration: EJK; Writing - original draft: HJL; Writing - review \& editing: EJK.

All authors have read and approved the manuscript.

\section{Acknowledgements}

All authors express their special appreciation to all participants in the Korea Youth Risk Behavior Survey.

\section{References}

1. World Health Organization. Water, sanitation, hygiene and waste management for the COVID-19 virus. World Health Organization Technical brief. 2020;1-9.

2. Curtis V, Cairncross S. Effect of washing hands with soap on diarrhrea risk in the community; A systematic review. Lancet Infect Dis. 2003;3:275-81.

3. Choi YS. Behaviors of hand washing practice Korean adolescents, 2011-2013: The Korea Youth Risk Behavior Web-based Survey. J Kor Acade-Industrial cooperation Soc. 2014;15:4132-8.

4. The 14th Korea Youth Risk Behavior Survey. Ministry of Education, Ministry of Health and Welfare, Centers for Disease Control and Prevention; 2018.

5. Park JH, Lee MJ, Goo HJ. Oral health-related quality of life according to oral health behavior and awareness of middle school students in some regions. J Kor Soc Dent Hyg. 2013;13:305-13.

6. Addy M, Hunter ML, Kingdon A, Dummer PM, Shaw WC. An 8-year study of changes in oral hygiene and periodontal health during adolescence. Int J Paediatr Dent. 1994;4:75-80.

7. David J, Wang NJ, Astrøm AN, Kuriakose S. Dental caries and associated factors in 12-year-old schoolchildren in Thiruvananthapuram, Kerala, India. Int J Paediatr Dent. 2005;15:420-8.

8. Park JH, Kim CS. Relationship between health behavior and oral symptoms in Korean adolescents. J Korean Soc Dent Hyg. 2015;15:813-21.

9. Oh JS, Lee SH. A Convergence Study on the Relationship of Body-Shape Perception and Periodontal Diseases in Female Adolescents. Journal of the Korea Convergence Society. 2019;10:287-97.

10. Statistics Korea. 2014 Adolescents Statistics Press Releases; 2014.

11. The 15th Korea Youth Risk Behavior Survey. Ministry of Education, Ministry of Health and Welfare, Centers for Disease Control and Prevention; 2019.

12. Tran D, Phongsavan P, Bauman AE, Havea D, Galea G. Hygiene Behaviour of Adolescents in the Pacific: Associations with Socio-demographic, Health behaviour and School Environment. Asia-Pac J Public He. 2006;18:3-11.

13. Taani DS, al-Wahadni AM, al-Omari M. The effect of frequency of toothbrushing on oral health of 14-16 year olds. J Irish Dent Association. 2003;49:15-20.

14. Borghi J, Guinness L, Ouedraogo J, Curtis V. Is hygiene promotion cost effective? A case study in Burkina Faso. Trop Med Int Health. 2020;7:960-9. 
15. Luby SP, Agboatwalla M, Feikin DR, Painter J, Billhimer W, Altaf A, Hoekstra RM. Effect of handwashing on child health: a randomised controlled trial. Lancet. 2005;366:225-33.

16. Ejere HOD, Alhassan MB, Rabiu M. Face washing promotion for preventing active trachoma. Cochrane Systematic Review. 2012; 003659.

17. Blencowe H, Cousens S, Mullany LC, Lee ACC, Kerber K, Wall S, Darmstadt GL, Lawn JE. Clean birth and postnatal care practices to reduce neonatal deaths from sepsis and tetanus: a systematic review and Delphi estimation of mortality effect. BMC Public Health. 2011;11:11;1-19.

18. Curtis V, Schmidt W, Luby S, Florez R, Touré O, Biran A. Hygiene: new hopes, new horizons. Lancet Infect Dis. 2011;11:312-21.

19. Greenland K, Cairncross S, Cumming O, Curtis V. Can we afford to overlook hand hygiene again? Trop Med Int Health. 2013;18:246-9.

20. Freeman MC, Clasen T, Brooker SJ, Akoko DO, Rheingans R. The impact of a school-based hygiene, water quality and sanitation intervention on soil-transmitted helminth reinfection: a cluster-randomized trial. The American Journal of Tropical Medicine Hygiene. 2013;89:875-83.

21. Petersen PE, Bourgeois D, Ogawa H, Estupinan-Day S, Ndiaye C. The global burden of oral diseases and risks to oral health. Bull World Health Organ. 2005;83:661-9.

22. Zaborskis A, Milciuviene S, Narbutaite J, Bendoraitiene E, Kavaliauskiene A. Caries experience and oral health behavior among 11-13-year-olds: an ecological study of data from 27 European countries, Israel, Canada and USA. Community Dent Health. 2010;27:102-8.

23. Park HJ. Factors that Influences Daily Toothbrushing Frequency and Use of Oral Health Care Products for Adolescents. The Journal of the Korea Contents Association. 2020;20:352-9.

24. Hwang MJ, Seong JM, Kim JH, Yoo SM, Park YD. The relationship between oral health behaviors and sociodemographic characteristics in Korean adolescents. J Korean Acad Dent Health. 2009;33:367-76.

25. Nzioka BM, Nyaga JK, Wagaiyu EG. The relationship between toothbrushing frequency and personal hygiene habits in Teenagers. East Afr Med J. 1993;70:445-8.

26. McKittrick TR, Jacobsen KH. Oral Hygiene and Handwashing Practices among Middle School Students in 15 Latin American and Caribbean Countries. West Indian Med J. 2015;64:266-8.

27. Umair Q. Saeed. Anwar. Hand washing behavior change effect of community-based hygiene and sanitation intervention in low resource setting. J public health. 2019;18:130.

28. Kwan SY, Petersen PE, Pine CM, Borutta A. Health-promoting schools: an opportunity for oral health promotion. Bull World Health Organ. 2005;83:677-85.

\section{Supplementary Files}

This is a list of supplementary files associated with this preprint. Click to download.

- Additionalfile11110.docx 